\title{
OPEN EDUCATIONAL RESOURCES IN GERMAN HIGHER EDUCATION - AN INTERNATIONAL PERSPECTIVE
}

Victoria I. Marín, Olaf Zawacki-Richter, Carl von Ossietzky University of Oldenburg, Svenja Bedenlier, Innovation in Learning Institute, University of Erlangen-Nuremberg, Germany

\begin{abstract}
The term Open Educational Resources (OER) is buzzword in education systems around the world and their potential has even been highlighted with the pandemic crisis as an aid in education systems. However, it is still far from reaching the promises that were envisaged for them. This is especially true for Germany, where challenges have been identified in terms of OER infrastructure and adoption at a macro, meso and micro level. In this study, factors such as OER infrastructure, policy, quality and change are considered in German higher education from an international perspective (Australia, Canada, China, Japan, South Africa, South Korea, Spain, Turkey and the United States). As part of a broader research project, this comparative case study between higher education (HE) systems internationally provides insights into OER that could be useful for other HE systems, institutions and faculty members moving towards OER in these times.
\end{abstract}

Keywords: Open educational resources (OER), Germany, higher education (HE), comparative case study, international view

\section{Introduction}

In a recent European index report on the readiness for digital lifelong learning (Beblavy, Baiocco, Kilhoffer, Akgüç, \& Jacquot, 2019) that referred to learning participation and outcomes, institutions and policies for digital learning, availability and use of digital learning, Germany ranked on the last position (the $27^{\text {th }}$ ), despite its top ranking in ICT according to the ICT Development Index (ITU, 2017). The report highlighted that, "while Germany has a strong economy and fairly good education system, investment in digital infrastructure and programs is sorely lacking," and "German policymakers are aware of the importance of digitalisation, but efforts to date lack ambition" (Beblavy et al., 2019; p.53). The German situation in terms of digital education has been covered by different 
authors, even recently, against the pandemic backdrop. For example, Kerres et al. (2020) specifically addressed the "contradictions between Germany's success in producing cutting-edge technology, and German caution when it comes to using digital technology in daily educational routines" (p.2).

When it comes to open educational resources (OER) and its infrastructure, recent reports highlight a similar situation. For instance, the UNESCO IITE (2019; p.27) stated that, "in Germany, OER adoption is also low, particularly outside the community of German OER experts in all sectors of education and training. OER are still considered as "not invented here' by most educators". For example, in higher education (HE), there are no guidelines/recommendations or national portals for knowledge/OER exchange. However, current projects are now addressing these aspects; for instance, the project EduArc (https://uol.de/coer/research-projects/projects/eduarc). This research project aims at modelling possible solutions to conceptualisations of either HE OER centralised repositories or hubs. In order to have the broader perspective in mind, an international comparative study covering different levels (macro, meso and micro level, see ZawackiRichter, 2009) was conducted by the Center for Open Education Research - COER (http://www.uol.de/coer).

In the current study we analyse the case of Germany and summarise the main aspects for infrastructure, policy, quality and change in OER in HE, and compare it with selected international country cases, concretely the COER members' countries of affiliation (Australia, Canada, China, Japan, South Africa, South Korea, Spain, Turkey and the United States). Therefore, this theoretical work is a summary of the results of the project devoted to the international comparison, including macro and meso levels, and the preliminary results of the micro level, which are currently being analysed.

\section{Method}

The study is based on a comparative case study in which we examined the research questions in the countries as cases to better understand the topic of OER and their infrastructures at the macro, meso and micro level, without intending to draw generalizable conclusions (Yin, 2009). The data used for the study are the written reports by COER experts, which were mainly based on desk research.

The research questions of the study are follows:

- What is the situation of OER in HE in terms of infrastructure, quality, policy and change in different countries at the macro, meso and micro level?

- How are macro, meso and micro levels regarding OER in HE connected to one another in different countries? 
Marín, V. I., Zawacki-Richter, O., \& Bedenlier, S.

Open Educational Resources in German Higher Education - An International Perspective

\section{Results and discussion}

We present a summary of the results according to the three above-mentioned levels in the different countries included in the study, starting with a more detailed description of the case of Germany. A final section synthesizes and summarizes the relationship between the levels.

\section{Macro level}

Contextual factors to understand national OER infrastructures, policies, quality assurance mechanisms and measures to promote change that were identified in the study were: each country's population, number of HE students, number of HE institutions, the balance between private and public HE system, the ICT development and the digital readiness. As a cornerstone element, the level of political structure centralisation impacted the four elements studied (Marín et al., 2020).

The case of Germany shows that many federal states are developing or have developed their own OER repositories (e.g. Baden-Württemberg), but there is no national repository, which also answers to the decentralised structure of the country in terms of education. The central hub that is one development option within the project EduArc may be an answer to that need (Kerres, Hölterhof, Scharnberg, \& Schröder, 2019). In terms of quality assurance, there are no national quality frameworks for OER but rather some institutional and individual efforts. Policy at the macro level consists of national recommendations, but digital strategies are being/have been developed in nearly all of the federal states (Bedenlier \& Deimann, 2020), although not all of them refer to OER explicitly. Government funding is the top-down driven activity for change. As a concrete example, a funding line targeted OER between 2012 and 2016 with different projects and services being developed, mostly devoted to promoting information about OER, encouraging educators to use and create OER and to develop some discipline-based materials (Mayrberger, 2019). In addition, there are other relevant organisms related to change and policy (Hochschulforum Digitalisierung). In this regard, Neumann, Orr, and Muuß-Merholz (2018, p. 259) remarked that "the coexistence and interaction of bottom-up and top-down driven activity is characteristic for the German OER movement".

In the international context, the country with the highest level of centralisation in its HE system was China, which was the exception in terms of having developed national standards for OER and infrastructure quality. Other countries considered as centralised were Japan, Spain, Turkey, South Africa, Australia and Korea. In some of these countries, national infrastructures for OER in HE were found (e.g. South Korea, Spain) but in others these infrastructures only exist for other education sectors or for other types of resources (e.g. Turkey). Other countries had checklists, guidelines and evaluation guides developed 
Marín, V. I., Zawacki-Richter, O., \& Bedenlier, S.

Open Educational Resources in German Higher Education - An International Perspective

by relevant consortia/organisations (e.g. Australia, South Korea, Spain). In terms of policy, laws or regulations that include OER infrastructure were present just in some centralised countries (e.g. South Korea, Turkey). Highly decentralised HE systems were identified in Canada and the United States. As in Germany, education is a mandate of provinces or states, resulting rather in underdeveloped or non-existent OER infrastructures on the national level, and rather non-binding recommendations published by different actors concerning policy. For all countries, change happens mostly in the form of national funding initiatives and national digital strategies; despite this, change was reported to happen mostly at the meso or micro level in the majority of countries (Marín et al., 2020).

\section{Mesolevel}

The institutional context was diverse and main aspects that influenced OER infrastructure could not be easily identified. Even within the same country, diverse examples of HE institutions dealing with OER infrastructure were noted. However, national regulations, government support and university and faculty evaluation were especially important at the institutional level for some countries. University leadership and co-participation in the process of designing policies for OER were also factors considered. Some of these factors were also mentioned as enablers and barriers in the institutional context in previous literature; others include cultural/institutional norms, funding, institutional policies (Cronin, 2017; Murphy, 2013).

In the case of Germany, a high number of OER regional networks was identified in connection to the federal states or as concrete HE consortia within federal states or between them (less common). Examples were the "NRW Digitale Hochschule" with $43 \mathrm{HE}$ institutions and the federal state ministry of culture and science in North RhineWestphalia, the "HE Network Digitisation of Teaching" in Baden-Württemberg or the Virtual University Bavaria. These consortia often developed OER shared infrastructures; for instance, the North Rhine-Westphalian consortium had a centralised HE OER repository, and the Virtual University Bavaria operated via a shared platform for the courses of the HE consortium. Regarding OER quality assurance, there were no institutional procedures, with the exception of the Hamburg Open Online University. In this context, of which a quality assurance framework and instrument for OER was developed (Mayrberger, Zawacki-Richter, \& Müskens, 2018). In terms of institutional policy, only a few HE institutions had a strategy for digitalisation, usually developed by the university leadership (in some universities combined with co-design processes with the educational community), and many were working on it; nevertheless, not the majority of them addressed OER (Gilch, Beise, Krempkow, Müller, Stratmann, \& Wannemacher, 2019). Up to date only Reutlingen University had a concrete OER policy; however, this was only a snapshot at the time of the desk research and needs to be revisited as more 
institutions develop their digitalisation policies. Regarding change, federal state funding and policy were important but their translation into practice was rather dependent on the individual HE institution, HEIs also had their concrete funding schemes, e.g. for innovative teaching and learning concepts that include OER approaches.

In countries like China and South Korea, top-down institutional quality assurance mechanisms derived from national regulations were common. In other countries these were either non-existent (e.g. Australia, South Africa) or based on own independent institutional guidelines (e.g. Japan, Spain, Canada). Government support and university and faculty evaluations were key in China and South Korea to extend OER initiatives and shared infrastructure across their HE institutions and regional networks. University leadership in developing policies was common in countries such a South Korea, Turkey and Australia. In some HE institutions in Spain and Canada, this leadership was combined to some extent with co-design processes with the educational community (e.g. active consultation or direct involvement). OER policies were not common but present in a few HE institutions in Spain and Australia. Institutional change was mostly reported as a mixture of top-down (institutional strategy, university leadership) and bottom-up approaches in many countries (e.g. Australia, Japan, South Africa, Canada); although it was remarked that bottom-up approaches were more frequent. The role of the university libraries in OER was especially emphasised in some of the countries in the study (e.g. Australia, Canada, Spain).

\section{Micro level}

The results regarding the micro level are currently being analysed and data from some countries is still being collected. At this level, individual faculty's perceptions regarding OER and their infrastructures were the focus. For Germany, a survey is being carried out in order to collect these perceptions.

The OER Adoption Pyramid could be used as a framework for understanding the different factors that facilitate or hinder the use and creation of OER by educators in HE (Trotter \& Cox, 2016), which in turn, are cross-sectional to the studied elements (infrastructure, policy, quality and change). The pyramid includes six factors: access, permission, awareness, capacity, availability and volition. While lack of access was mostly noted in the Global South (Cox \& Trotter, 2017), aspects of awareness, capacity, availability and volition were among the most common in the countries studied in our preliminary findings. However, permission in terms of copyright licencing/policies by the institution was present in some of the countries (e.g. Turkey, South Africa, Canada).

In terms of awareness, Turkey's faculty members showed a low awareness regarding the philosophy of openness. In the Canadian province of Ontario, academics were rather 
Marín, V. I., Zawacki-Richter, O., \& Bedenlier, S.

Open Educational Resources in German Higher Education - An International Perspective

unaware of OER (Hayman, 2018) and these data seemed to reflect other provinces in the country, despite having several OER forerunners in some Canadian universities. In South Africa, an OER awareness seemed clear in some institutions, but academics had a limited understanding concerning open licensing formats and processes, especially regarding OER creation (de Hart, Chetty, \& Archer, 2015). On the opposite side, Japan's academics were identified as well or somewhat aware of OER (Shigeta et al., 2017). Referring to OER policies' awareness, in China, faculty members had a low awareness regarding OER policies. Similarly, a majority of Spanish educators were not aware of OER policy procedures.

Concerning capacity, technical skills for using and finding OER were mentioned as barriers for OER adoption. For example, a shortage of digital skills among the educators was identified as a barrier in Turkey. In Canada, the need for educators to improve their OER-related skills, such as finding appropriate materials, was frequently mentioned. This connects to the factor of availability of OER and their repositories. For instance, the lack of appropriate OER was remarked by Canadian educators, referring to the OER fit to the teaching content and educators' standards. Similarly, Spanish educators highlighted as the most relevant reason for the lack of use of institutional OER repositories that they did not find OER useful for their teaching. The quality of OER and the lack of availability of context relevant OER, as well as the lack of adequate infrastructure to assist and support the use and creation of OER, were challenges highlighted by educators in South Africa (de Hart, Chetty, \& Archer, 2015; Madiba, 2018). In Turkey, OER repositories did not function fully and had restrictions that hindered the dissemination of OER. All the countries studied emphasised the importance of faculty professional development and technical and pedagogical support to reach individual capacity, but also to increase OER awareness and understanding.

In terms of volition, resistance to adopt OER was identified in different cases, especially regarding the creation, sharing and remix of OER. For instance, Turkey's faculty members hesitated to open up their materials because others might use them for their own use (either for profit or not) and would not cite them. In the case of Canada, faculty members, with the exception of OER forerunners, did not want to release their intellectual property, but they would be willing to share within limited parameters - within their own department, for example, or with close colleagues. Most of the countries highlighted the lack of sufficient incentives for OER use and creation (e.g. South Africa, Canada, Spain), and suggested the relevance of establishing different types of incentives to support individual volition; e.g. monetary incentives (as in South Korea, China), faculty evaluation points (as in South Korea and Turkey), reduction in teaching load or assignment of teaching assistants (as in Japan, China). 


\section{Macro, meso and micro levels}

Although there are important differences in terms of OER infrastructure, policy, quality and change in HE in the countries studied, similarities in the relations between the levels seem to outnumber. In Figure 1 the relations are represented according to the corresponding level (macro, meso and micro level) and the elements studied (infrastructure, policy, quality and change).

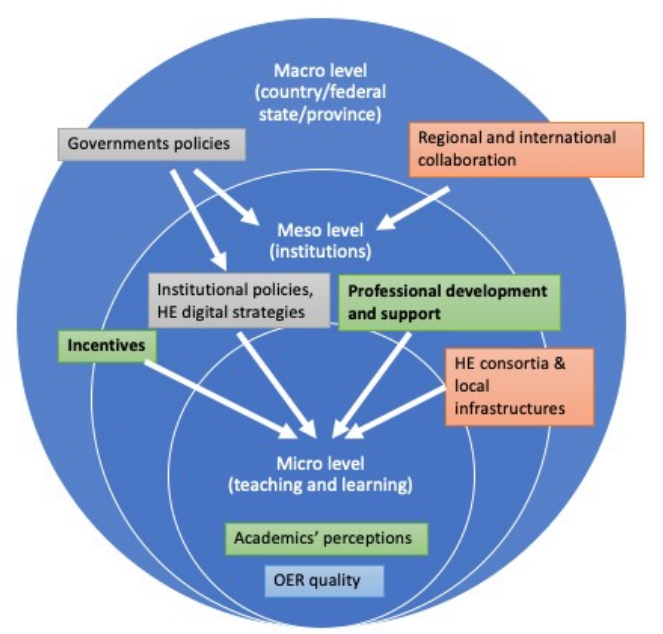

Figure 1. Relationships between the elements and the levels. Elements are distinguished by background colour (orange for infrastructures, grey for policy, cyan for quality and green for change)

The figure shows that relationships between the levels could have multiple factors and impacts, usually top-down. In the case of infrastructure and policy, there are clearly commonly top-down approaches that influence institutions and, in turn, the teaching and learning level. On the other hand, quality is mostly considered from a micro level perspective, even though international and national models may have a reduced impact. For the promotion of change, the application of incentives of diverse kind and the use of the institutional offer for professional development and support seem to be key for the OER adoption at the individual level. However, academics' perceptions are suggested to play a relevant role in the final step to adopt OER.

\section{Conclusions}

According to Gumb (2020) citing DeRosa's words, “OER can remove barriers for students and faculty who need to shift to more ubiquitously available resources" and "Open is about public infrastructure more than it is a set of free textbooks". As it was evident in our comparative study, there are still many challenges to overcome for this to be a reality, despite the pressing situation in which OER are more relevant than ever. A good starting point seems to be the development of supportive open education institution policies that include incentives and capacity building within faculty members to work with OER, as it 
Marín, V. I., Zawacki-Richter, O., \& Bedenlier, S.

Open Educational Resources in German Higher Education - An International Perspective

was also recommended by Huang, Tili, Chang, Zhang, Nascimbeni, and Burgos (2020). Although this may prove to be useful at the institutional level, macro level aspects should not be underestimated, since they set up the general framework for HE in terms of infrastructure, policy, quality and change. On the other hand, micro level aspects are affected by both macro and meso levels, but it is ultimately individual faculty members who decide about OER use and creation. Therefore, these aspects should be considered within the whole OER adoption ecosystem (Cox \& Trotter, 2017).

Despite the limitations of the study in terms of type of data collection, this study contributes to the field by offering an international view on OER from three interrelated levels and suggests potentials and difficulties of HE systems for other countries. Future research will include a deep analysis of the micro level.

\section{References}

Beblavy, M., Baiocco, S., Kilhoffer, Z., Akgüç, M., \& Jacquot, M. (2019). Index of Readiness for Digital Lifelong Learning: Changing How Europeans Upgrade Their Skills. CEPS Report. Retrieved from https://www.ceps.eu/cepspublications/index-of-readiness-fordigital-lifelong-learning/

Bedenlier, S., \& Deimann, M. (2020). 'Bildung' und 'Digitalisierung' im Spiegel von Digitalisierungsstrategien. Zeitschrift für Hochschulentwicklung, 15(1), 41-59. Retrieved from https://zfhe.at/index.php/zfhe/article/view/1317

Cox, G. \& Trotter, H. (2017). An OER framework, heuristic and lens: Tools for understanding lecturers' adoption of OER. Open Praxis, 9(2), 151-171. http://dx.doi.org/10.5944/openpraxis.9.2.571

Cronin, C. (2017). Openness and praxis: Exploring the use of open educational practices in higher education. The International Review of Research in Open and Distributed Learning, 18(5). https://doi.org/10.19173/irrodl.v18i5.3096

Gilch, H., Beise, A. S., Krempkow, R., Müller, M., Stratmann, F., \& Wannemacher, K. (2019). Digitalisierung der Hochschulen Ergebnisse einer Schwerpunktstudie für die Expertenkommission Forschung und Innovation. Retrieved from https://www.efi.de/fileadmin/Innovationsstudien_2019/StuDIS_14_2019.pdf

Gumb, L. (2020). What's “Open” during COVID-19? In Global Pandemic, OER and Open Access Matter More than Ever. New England Journal of Higher Education, April 2020. Retrieved from https://nebhe.org/journal/whats-openduring-covid-19-in-globalpandemic-oer-and-open-access-matter-more-than-ever/ 
Marín, V. I., Zawacki-Richter, O., \& Bedenlier, S.

Open Educational Resources in German Higher Education - An International Perspective

de Hart, K. L., Chetty, Y. B., \& Archer, E. (2015). Uptake of OER by staff in distance education in South Africa. International Review of Research in Open and Distributed Learning, 16(2), 18-45. https://doi.org/10.19173/irrodl.v16i2.2047

Hayman, J. (2018). Awareness and Use of Open Educational Resources (OER) in Ontario: A Preliminary Study of Post-Secondary Educator Perspectives. eCampusOntario.

Retrieved from

https://www.ecampusontario.ca/wpcontent/uploads/2018/10/eCampusOntario_Sept ember2018_ResearchReport.pdf

Huang, R., Tlili, A., Chang, T., Zhang, X., Nascimbeni, F., \& Burgos, D. (2020). Disrupted classes, undisrupted learning during COVID-19 outbreak in China: application of open educational practices and resources. Smart Learning Environments, 7(19). https://doi.org/10.1186/s40561-020-00125-8

ITU. (2017). ICT Development Index 2017. Retrieved from https://www.itu.int/net4/ITUD/idi/2017/

Kerres, M. (2020). Against All Odds: Education in Germany Coping with Covid-19. Postdigital Science and Education, 2, 640-694. https://doi.org/10.1007/s42438-02000130-7

Kerres, M., Hölterhof, T., Scharnberg, G., \& Schröder, N. (2019). EduArc. Eine Infrastruktur zur hochschulübergreifenden Nachnutzung digitaler Lernmaterialien. Synergie, 07, 66-69. Retrieved from https://uhh.de/en4om

Madiba, A. M. (2018). Lecturers' perceptions and experiences of open educational resources in teaching and learning. Doctoral dissertation. University of the Free State, South Africa. Retrieved from http://hdl.handle.net/11660/9053

Marín, V. I., Bond, M., Zawacki-Richter, O., Aydin, C. H., Bedenlier, S., Bozkurt, A., Conrad, D., Jung, I., Kondakci, Y., Prinsloo, P., Qayyum, A., Roberts, J., Sangrà, A., Slagter van Tryon, P. J., Veletsianos, G., \& Xiao, J. (2020). A Comparative Study of National Infrastructures for Digital (Open) Educational Resources in Higher Education. Open Praxis, 12(2), 241-256. https://doi.org/10.5944/openpraxis.12.2.1071

Mayrberger, K. (2019). Projekte der BMBF-Förderung OERinfo 2017/2018. Sonderband zum Fachmagazin Synergie: Universität Hamburg. Retrieved from https://www.synergie.uni-hamburg.de/media/sonderbaende/sonderband-synergieoerinfo-projekte-2017-18-oerinfo.pdf

Mayrberger, K., Zawacki-Richter, O., \& Müskens, W. (2018). Qualitätsentwicklung von OER - Vorschlag zur Erstellung eines Qualitätssicherungsinstrumentes für OER am Beispiel der Hamburg Open Online University. Universität Hamburg. https://doi.org/10.25592/978.3.924330.67.5 
Murphy, A. (2013). Open educational practices in higher education: Institutional adoption and challenges. Distance Education, 34(2), 201-217. https://doi.org/10.1080/01587919.2013.793641

Neumann, J., Orr, D., \& Muuß-Merholz, J. (2018). Open Educational Resources in Germany State of development and some initial lessons learned. EmRede Revista de Educacao a Distancia, 5(2), 259-270. Retrieved from https://www.aunirede.org.br/revista/index.php/emrede/article/view/335

Shigeta, K., Koizumi, M., Sakai, H., Tsuji, Y., Inaba, R., \& Hiraoka, N. (2017). A survey of the awareness offering, and adoption of OER and MOOcs in Japan. Open Praxis, 9(2), 195-206. http://dx.doi.org/10.5944/openpraxis.9.2.568

Trotter, H., \& Cox, G. (2016) The OER Adoption Pyramid. Proceedings of Open Education Global 2016. Krakow, Poland. Retrieved from http://open.uct.ac.za/handle/11427/18936

UNESCO IITE. (2019). Understanding the Impact of OER: Achievements and Challenges. Moscow, Russian Federation.

Yin, R. K. (2009). Case Study Research. Design and Methods ( $4^{\text {th }}$ ed.). CA: Sage Publications.

Zawacki-Richter, O. (2009). Research Areas in Distance Education: A Delphi Study. The International Review of Research in Open and Distributed Learning, 10(3). https://doi.org/10.19173/irrodl.v10i3.674

\section{Acknowledgements}

We would like to thank all the COER experts involved in the country study reports.

This article is part of the macro level report of the work package 11 of the project "Digital educational architectures: Open learning resources in distributed learning infrastructures - EduArc" funded by the German Federal Ministry of Education and Research (grant \#16DHB2129). 